\title{
Short-term outcomes of endovascular repair of abdominal aortic aneurysm, including ruptured cases
}

\author{
Piotr Kulig, Krzysztof Lewandowski, Bartłomiej Banaś, Piotr Piekorz, Andrzej Kostka, Maciej Zaniewski \\ Department of Vascular Surgery and Angiology, Brothers of Mercy St. John of God Hospital, Krakow, Poland
}

Videosurgery Miniinv 2018; 13 (2): 243-249

DOI: https://doi.org/10.5114/wiitm.2018.73358

\begin{abstract}
Introduction: Endovascular aneurysm repair as a minimally invasive alternative has become a commonly used surgical method for treating patients with abdominal aortic aneurysm (AAA).

Aim: To analyze short-term outcomes of endovascular treatment of AAA patients, including ruptured cases.

Material and methods: From 2010 to 2015, 247 patients with AAA were treated using the endovascular aneurysm repair technique. A short-term analysis was conducted - up to 30 days after surgery. It included 236 patients with planned surgery and 11 operated on in emergency mode, due to ruptured AAA.

Results: Rates of short-term mortality and re-interventions among patients undergoing planned surgery were $2.5 \%$ and $4.2 \%$, respectively. Surgical complications occurred in 18 (7.6\%) patients, with the most common being thrombosis and blockage of the stent graft (2.5\%). Systemic complications were found in 19 (8\%) planned cases, with the most common being arrhythmias (1.7\%). In patients with ruptured AAA, short-term mortality was 36.4\%, while re-interventions were performed in $3(27.3 \%)$ patients. Rates of surgical and systemic complications for ruptured AAA were $45.4 \%$ and $72.7 \%$, respectively.

Conclusions: The AAA patients undergoing endovascular aneurysm repair showed relatively low short-term mortality. However, larger groups of patients with ruptured AAA are required in order to assess the outcomes in this sub-population.
\end{abstract}

Key words: abdominal aortic aneurysm, short-term outcomes, endovascular aneurysm repair.

\section{Introduction}

Endovascular stent graft implantation as an alternative to open conventional surgery is becoming a commonly used therapeutic method for abdominal aortic aneurysm (AAA). Worldwide, the endovascular technique is used in $43-74 \%$ of patients treated because of AAA [1-3]. The relatively low invasiveness of the endovascular method allows the procedure to be performed under local anesthesia, with less trauma and less perioperative pain. The potential benefits of the endovascular method also include shorter hospitalization and a reduction in the rates of perioperative complications and mortality [3-7].

Despite potential benefits, the minimally invasive method is associated with more frequent re-interventions, resulting mainly from the occurrence of a leak. The latter fact causes that the advantage of perioperative results decreases during long-term follow-up [8-11]. The cost of equipment needed to carry out endovascular surgery is higher than the cost of performing an open conventional operation. However, taking into account the much lower invasiveness of the endovascular method, such repair of 
AAA may prove to also be a viable treatment for economic reasons $[3,12]$.

\begin{abstract}
Aim
A database of patients with AAA who underwent endovascular repair was created in the Department of Vascular Surgery and Angiology at the Brothers of Mercy St. John of God Hospital in Krakow. In this study, we have analyzed short-term outcomes to evaluate occurrence of complications of the endovascular technique within 30 days after this minimally invasive repair. The short-term observation included mortality, surgical and systemic complications, and re-interventions in patients subject to treatment for elective and ruptured AAA.
\end{abstract}

\section{Material and methods}

Between 2010 and 2015, 247 patients with AAA underwent endovascular repair in the Department of Vascular Surgery and Angiology at the Brothers of Mercy St. John of God Hospital in Krakow. All data for patients and treatment results were recorded in the hospital's MLS MedicAll computer system and in Microsoft Office Excel software. Among the patients analyzed, there were 236 planned interventions, while 11 patients were subject to emergency operations due to a ruptured AAA. The patient's qualification for endovascular repair was based primarily on the anatomy of the AAA, age and general condition of the patient. Prior to the operation, basic biochemical blood tests and echocardiography were performed, and the risk of perioperative mortality was determined using the P-Possum scale. In the case of pre-surgical imaging diagnostics, all of the patients were subjected to computed tomography angiography (angio-CT) of the abdominal aorta, using a 32-row spiral AQUILION 32 CT scanner manufactured by Toshiba. According to the angio-CT imaging, patients were qualified for intervention based on diameter of the AAA above $5-5.5 \mathrm{~cm}$, widening diameter over $0.5-1.0 \mathrm{~cm}$ per year or features of ruptured AAA. Some of the patients also suffered from thoracic aortic aneurysms and aneurysms of the iliac artery that were subjected to simultaneous treatment during the same procedure.

All repairs were performed in the Endovascular Therapy Unit of the hospital, using dedicated radiological equipment (Philips). Local or subarachnoid anesthesia was used in the majority of the patients treated electively, with a few cases of general anesthesia. All patients with ruptured AAA were treated under general anesthesia. Stent grafts were deployed using systems of various manufacturers, including Zenith COOK, Endurant Medtronic, Excluder Gore, Jotec E-tegra, and others.

The short-term outcomes, including mortality, surgical and systemic complications, and re-interventions, were recorded within the 30-day period after the repair. As the anticipated outcomes differ markedly between planned and emergency interventions, the short-term results were analyzed separately for these two groups of patients.

\section{Statistical analysis}

The Mann-Whitney $U$ test and the $\chi^{2}$ test were used where appropriate to compare the distribution of individual variables between AAA patients treated in planned and emergency settings. $P$-value $<0.05$ was considered statistically significant in a two-tailed analysis. Statistical analysis was performed using the Statistica 12 software package (StatSoft Polska).

\section{Results}

The study population consisted mostly of male elderly patients with numerous co-morbidities. The risk of perioperative mortality calculated according to the P-Possum score was significantly lower in patients with elective AAA repair. The median hemoglobin level was significantly lower in patients with ruptured AAA (10.8 g/dl, IQR: 7.4-14.4) compared to elective patients with AAA (13.4 g/dl, IQR: 12.014.4) (Table I).

Based on the angio-CT imaging, the median AAA diameter was $59 \mathrm{~mm}$ (IQR: 54-64.7) in unruptured cases and $60 \mathrm{~mm}$ (IQR: 58.5-76.5) in ruptured cases. Clinical manifestations of AAA were recorded in 45 (19.1\%) elective patients. No significant differences in the median duration of surgery and the median length of hospitalization were noted between the patients with unruptured and ruptured AAA (Table II).

In 236 patients undergoing planned interventions, short-term mortality was $2.5 \%$ and surgical complications occurred in 18 (7.6\%) patients. Thrombosis and blockage of the stent graft with acute ischemia of the lower limb was reported in 6 (2.5\%) patients. In 6 cases leaks occurred - type I (3 patients) and type II (3 patients) - whereas $4(1.7 \%)$ and $2(0.8 \%)$ patients respectively had an infection of the 
Table I. Demographic and clinical-pathological characteristics of the studied group of patients

\begin{tabular}{|c|c|c|c|}
\hline Parameter & $\begin{array}{l}\text { Unruptured abdominal aortic } \\
\text { aneurysm }\end{array}$ & $\begin{array}{l}\text { Ruptured abdominal aortic } \\
\text { aneurysm }\end{array}$ & $P$-value \\
\hline Number of patients & 236 & 11 & \\
\hline Age [years] median (IQR) & $75(69-80)$ & $71(65.5-76.5)$ & $0.196^{\star}$ \\
\hline Male/female, $n(\%)$ & $204(86.4) / 32(13.6)$ & $10(90.9) / 1(9.1)$ & $0.690^{\dagger}$ \\
\hline \multicolumn{4}{|l|}{ Comorbidities, $n$ (\%): } \\
\hline General arteriosclerosis & $84(35.6)$ & $6(54.5)$ & $0.035^{\dagger}$ \\
\hline Blood hypertension & $127(53.8)$ & $5(45.4)$ & $0.587^{\dagger}$ \\
\hline Ischemic heart disease & $122(51.6)$ & $5(45.4)$ & $0.686^{+}$ \\
\hline Heart valve disorders & $17(7.2)$ & $2(18.2)$ & $0.182^{\dagger}$ \\
\hline Arrhythmia & $37(15.6)$ & $1(9.1)$ & $0.554^{\dagger}$ \\
\hline Diabetes mellitus & 47 (19.9) & $4(36.3)$ & $0.188^{\dagger}$ \\
\hline Chronic renal failure & $21(8.9)$ & $2(18.2)$ & $0.300^{\dagger}$ \\
\hline Lung disease & $34(14.4)$ & $3(27.3)$ & $0.243^{\dagger}$ \\
\hline Thyroid disease & $19(8.0)$ & $1(9.1)$ & $0.239^{\dagger}$ \\
\hline Oncological disease & $17(7.2)$ & $0(0)$ & $0.345^{\dagger}$ \\
\hline Nicotine addiction, $n(\%)$ & $61(25.8)$ & $3(27.3)$ & $0.916^{\dagger}$ \\
\hline Ejection fraction (\%), median (IQR) & $55(43-60)$ & $50(47-55)$ & $0.910^{*}$ \\
\hline P-Possum mortality (\%), median (IQR) & $15(9.2-22.3)$ & $28(23.5-32.6)$ & $0.044^{*}$ \\
\hline Hemoglobin [g/dl], median (IQR) & $13.4(12-14.4)$ & $10.8(7.4-14.4)$ & $0.045^{\star}$ \\
\hline Urea [mmol/l], median (IQR) & $7.7(6-9.7)$ & $11.1(6.5-16.3)$ & $0.007^{*}$ \\
\hline Creatinine [mmol/l], median (IQR) & $95(79-121.7)$ & $105(85-131.7)$ & $0.098^{*}$ \\
\hline
\end{tabular}

wound in the groin and bleeding from the wound in the groin. Systemic complications in short-term follow-up occurred in 19 (8\%) patients undergoing elective AAA repair. The most common were arrhythmia (1.7\%), myocardial infarction (1.3\%), exacerbation of ischemic heart disease (1.3\%) and pneumonia (1.3\%). Ten (4.2\%) patients required re-interventions after elective endovascular treatment (Table III).

All patients with thrombosis and blockage of the stent graft with acute ischemia of the lower limb required re-interventions. In 5 cases femorofemoral bypass surgery was carried out, and 1 patient was subject to thrombectomy of the left and right branch of a stent graft, with angioplasty and implantation of a stent in the right branch of a stent graft. In all patients with type I leak during short-term observation, re-intervention was also performed, which consisted of stent graft reimplantation. Patients with type II leak and infection of the wound in the groin did not require any surgical intervention. In 1 patient with bleeding from the wound in the groin, a surgical revision of the wound was performed, with hemostasis and hematoma evacuation, while in the case of 1 patient conservative treatment and compression were applied.

In patients with ruptured AAA, short-term mortality was $36.4 \%$. Surgical and systemic complications in this group occurred in $45.4 \%$ and $72.7 \%$ of patients, respectively. The most common surgical complications were leaks, which occurred in 3 patients. Re-interventions were carried out in 3 (27.3\%) patients (Table III).

In patients with type I and III leaks, reimplantation of the stent grafts took place, while in the case of the patient with intestinal necrosis left hemicolectomy and colostomy were performed. In patients with type II leak and infection of the wound in the groin, no surgical intervention was required.

\section{Discussion}

In Poland, the endovascular method is the only treatment alternative for conventional open sur- 
Table II. Characteristics of abdominal aortic aneurysm (AAA) and perioperative features of the implanted stent graft

\begin{tabular}{|c|c|c|c|}
\hline Parameter & $\begin{array}{l}\text { Unruptured abdominal aortic } \\
\text { aneurysm }\end{array}$ & $\begin{array}{l}\text { Ruptured abdominal } \\
\text { aortic aneurysm }\end{array}$ & $P$-value \\
\hline Number of patients & 236 & 11 & \\
\hline AAA diameter [mm], median (IQR) & $59(54-64.7)$ & $60(58.5-76.5)$ & $0.657^{\star}$ \\
\hline Symptomatic AAA, yes/no, $n(\%)$ & $45(19.1) / 191(80.9)$ & $11(100) / 0(0)$ & $<0.001^{\dagger}$ \\
\hline \multicolumn{4}{|l|}{ Additionally, aneurysm of iliac arteries, $n(\%)$ : } \\
\hline Right common iliac artery & $58(24.6)$ & $3(27.3)$ & $0.839^{\dagger}$ \\
\hline Left common iliac artery & $52(22)$ & $3(27.3)$ & $0.683^{\dagger}$ \\
\hline Right external iliac artery & $1(0.4)$ & $0(0)$ & $0.829^{\dagger}$ \\
\hline Right internal iliac artery & $7(2.8)$ & $1(9.1)$ & $0.262^{+}$ \\
\hline Left external iliac artery & $0(0)$ & $0(0)$ & \\
\hline Left internal iliac artery & $14(5.9)$ & $0(0)$ & $0.406^{+}$ \\
\hline Additionally, thoracic aorta aneurysm, $n(\%)$ & $3(1.2)$ & $0(0)$ & $0.707^{\dagger}$ \\
\hline \multicolumn{4}{|l|}{ Anesthesia, $n(\%)$ : } \\
\hline Local & $105(44.5)$ & $0(0)$ & $0.004^{\dagger}$ \\
\hline Subarachnoid & $86(36.4)$ & $0(0)$ & $0.013^{\dagger}$ \\
\hline General & 45 (19.1) & $11(100)$ & $<0.001^{\dagger}$ \\
\hline Operation time [min], median (IQR) & $105(88.7-125.0)$ & $110(105-130)$ & $0.937^{\star}$ \\
\hline \multicolumn{4}{|l|}{ Type of implanted stent graft, $n(\%)$ : } \\
\hline Zenith COOK & $69(29.3)$ & $1(9.1)$ & $0.147^{\dagger}$ \\
\hline Endurant Medtronic & $78(33.1)$ & $9(81.8)$ & $0.001^{\dagger}$ \\
\hline Excluder Gore & $36(15.2)$ & $0(0)$ & $0.161^{\dagger}$ \\
\hline Jotec E-tegra & $47(19.9)$ & $1(9.1)$ & $0.375^{\dagger}$ \\
\hline Other & $6(2.5)$ & $0(0)$ & $0.592^{\dagger}$ \\
\hline Covering of external iliac arteries, yes/no, $n(\%)$ & $87(36.9) / 149(63.1)$ & $4(36.4) / 7(63.6)$ & $0.973^{\dagger}$ \\
\hline $\begin{array}{l}\text { Volume of administered Optiray contrasting } \\
\text { agent }[\mathrm{ml}] \text {, median }(\mathrm{IQR})\end{array}$ & $110(97.5-132.5)$ & $130(110-150)$ & $0.688^{*}$ \\
\hline Hospitalization [days], median (IQR) & $6(4-8)$ & $7(5-9)$ & $0.090^{*}$ \\
\hline
\end{tabular}

gery of AAA patients due to technical problems and a long learning curve associated with laparoscopic procedures and the high costs of the robotic system. In the current study, the short-term outcomes were analyzed in patients with elective and ruptured AAA subject to endovascular treatment between 2010 and 2015. The basic parameters proving the efficiency of the endovascular repair, such as mortality, surgical and systemic complications and re-interven- tions, were examined up to 30 days after interventions.

Due to the low invasiveness, less trauma and perioperative pain, as well as shorter hospitalization time and faster return to full fitness, the endovascular technique is becoming the preferred treatment for AAA patients worldwide [1-7]. In a UK study, AAA patients undergoing planned endovascular treatment were found to have low rates of short- 
Table III. Short-term observation after endovascular treatment of the studied group of patients

\begin{tabular}{|c|c|c|c|}
\hline $\begin{array}{l}\text { Short-term observation (up to } 30 \text { days after } \\
\text { operation) }\end{array}$ & $\begin{array}{l}\text { Unruptured abdominal } \\
\text { aortic aneurysm }\end{array}$ & $\begin{array}{l}\text { Ruptured abdominal } \\
\text { aortic aneurysm }\end{array}$ & $P$-value ${ }^{\dagger}$ \\
\hline Number of patients & 236 & 11 & \\
\hline Mortality, $n(\%)$ & $6(2.5)$ & $4(36.4)$ & $<0.001$ \\
\hline Surgical complications, $n$ (\%): & $18(7.6)$ & $5(45.4)$ & $<0.001$ \\
\hline Type I leak & $3(1.3)$ & $1(9.1)$ & 0.045 \\
\hline Type II leak & $3(1.3)$ & $1(9.1)$ & 0.045 \\
\hline Type III leak & $0(0)$ & $1(9.1)$ & $<0.001$ \\
\hline $\begin{array}{l}\text { Thrombosis and stent graft blockage with acute } \\
\text { ischemia of a lower limb }\end{array}$ & $6(2.5)$ & $0(0)$ & 0.592 \\
\hline Bleeding from wound in the groin & $2(0.8)$ & $0(0)$ & 0.759 \\
\hline Infection of wound in the groin & $4(1.7)$ & $1(9.1)$ & 0.089 \\
\hline Intestinal necrosis & $0(0)$ & $1(9.1)$ & $<0.001$ \\
\hline Systemic complications, $n$ (\%): & $19(8.0)$ & $8(72.7)$ & $<0.001$ \\
\hline Arrhythmia & $4(1.7)$ & $2(18.2)$ & $<0.001$ \\
\hline Myocardial infarction & $3(1.3)$ & $1(9.1)$ & 0.045 \\
\hline Exacerbation of coronary heart disease & $3(1.3)$ & $1(9.1)$ & 0.045 \\
\hline Pneumonia & $3(1.3)$ & $2(18.2)$ & $<0.001$ \\
\hline Exacerbation of chronic renal failure & $2(0.8)$ & $1(9.1)$ & 0.015 \\
\hline Clostridium difficile infection & $2(0.8)$ & $0(0)$ & 0.759 \\
\hline Infection of the urinary tract & $2(0.8)$ & $1(9.1)$ & 0.015 \\
\hline Re-interventions, $n$ (\%) & $10(4.2)$ & $3(27.3)$ & $<0.001$ \\
\hline
\end{tabular}

term mortality and complications - 0\% and 12\%, respectively. However, the study was conducted in young patients with a low perioperative risk [13]. Prospective randomized controlled trials including the elderly population also showed low short-term mortality in elective patients with AAA after stent graft implantation (0.5-1.7\%) [14-17]. The shortterm mortality in patients undergoing planned surgery in the current study was $2.5 \%$. Gnus et al. reported mortality of $1.5 \%$, while Ziaja et al. and an Asian study did not show short-term mortality in patients with AAA after elective endovascular aneurysm repair. What is worth mentioning, Morisaki et al. conducted a study on an elderly population over 80 years of age on average [7, 18, 19]. In the analysis conducted by Schermerhorn et al., patients undergoing a planned endovascular operation due to AAA showed decreasing short-term mortality during long-term follow-up from $4.9 \%$ to $2.4 \%$. The latest global multicenter report for this group of patients comparing the two periods 2005-2009 and 2010-2013 indicated a decrease of mortality rate from $1.5 \%$ to $1.1 \%$ [20-22].

Short-term mortality in ruptured AAA in US reports was $25.9-44.1 \%$ [3, 5, 20]. In this study, shortterm mortality for this group of patients was $36.4 \%$. Similar mortality rates (35.4\%) were shown by a randomized controlled trial in Europe, while Raats et al. reported a perioperative mortality rate of $30 \%$ [9, 20]. Other European reports on this group of patients show short-term mortality rates of $21.6-46.3 \%$ [6, $23,24]$. The lowest short-term mortality for patients with ruptured AAA after endovascular aneurysm repair is reported by a Dutch publication - 20\% [25]. In the latest Italian study for endovascular treatment involving AAA-ruptured patients, there was a signif- 
icant difference in short-term mortality for men and women, $22.2 \%$ and $40 \%$, respectively. Tan et al. reported a relatively high rate of the analyzed parameter after endovascular treatment of ruptured AAA in the elderly $-41 \%[26,27]$.

In this study, we conducted an analysis of the short-term results of AAA treatment using the endovascular method, in the case of both scheduled and emergency interventions. The large number of patients (236) included in the study allows for a reliable assessment of the endovascular method for scheduled repair. On the other hand, there is a relatively low number of patients (11) with ruptured AAA in the analysis. In addition, there are no middle- or long-term observations in the study, which would allow, inter alia, an assessment of the incidence of late surgical re-interventions.

\section{Conclusions}

The short-term therapeutic outcomes obtained in patients operated both in scheduled and emergency mode due to ruptured AAA are similar to the results of global reports on this subject. In patients with AAA provided with planned treatment, short-term mortality was $2.5 \%$, while world reports mention $0-4.9 \%$ [7, 13-21]. Short-term mortality in patients with emergency surgery due to the AAA rupture was $36.4 \%$, and in the case of global reports it was $20-46.3 \%[3,5,6,9,22-27]$.

\section{Conflict of interest}

The authors declare no conflict of interest.

\section{References}

1. Hiromatsu S, Sakashita H, Okazaki T, et al. Perioperative out comes for elective open abdominal aortic aneurysm repair since the adoption of endovascular grafting procedures. Eur J Vasc Endovasc Surg 2011; 42: 178-84.

2. IMPROVE Trial Investigators, Grieve R, Gomes M, et al. Endovascular strategy or open repair for ruptured abdominal aortic aneurysm: one-year outcomes from the IMPROVE randomized trial. Eur Heart J 2015; 36: 2061-9.

3. Dua A, Kuy S, Lee CJ, et al. Epidemiology of aneurysm repair in the United States from 2000 to 2010. J Vasc Surg 2014; 59: 1512-7.

4. Thomas D, Anderson D, Hulten E, et al. Open versus endovascular repair of abdominal aortic aneurysm: incidence of cardiovascular events in 632 patients in a department of defense cohort over 6-year follow-up. Vascular 2015; 23: 234-9.

5. Mohan PP, Hamblin MH. Comparison of endovascular and open repair of ruptured abdominal aortic aneurysm in the United
States in the past decade. Cardiovasc Intervent Radiol 2014; 37: 337-42.

6. Gunnarsson K, Wanhainen A, Djavani G, et al. Endovascular versus open repair as primary strategy for ruptured abdominal aortic aneurysm: a national population-based study. Eur J Vasc Endovasc Surg 2016; 51: 22-8.

7. Gnus J, Ferenc S, Dziewiszek M, et al. Comparison of endovascular aneurysm repair with open repair in patients with abdominal aortic aneurysm in our own material in years 2002 2011. Adv Clin Exp Med 2015; 24: 475-9.

8. Chang D, Parina R, Wilson S. Survival after endovascular vs open aortic aneurysm repairs. JAMA Surg 2015; 150: 1160-6.

9. Raats JW, Fluh HC, Ho GH, et al. Long-term outcome of ruptured abdominal aortic aneurysm: impact of treatment and age. Clin Interv Aging 2014; 9: 1721-1732.

10. Wojtaszek M, Wnuk E, Maciag R, et al. Improving the results of transarterial embolization of type 2 endoleaks with the embolic polymer Onyx. Videosurgery Miniinv 2016; 11: 259-67.

11. Synowiec T, Warot M, Burchardt P, et al. All dangerous types of endoleaks after endovascular aneurysm repair in a single patient. Videosurgery Miniinv 2015; 10: 290-4.

12. Van Beek SC, Vahl A, Wisselink W, et al. Midterm re-interventions and survival after endovascular versus open repair for ruptured abdominal aortic aneurysm. Eur J Vasc Endovasc Surg 2015; 49: 661-8.

13. Sandford RM, Choke E, Bown MJ, et al. What is the best option for elective repair of an abdominal aortic aneurysm in a young fit patient? Eur J Vasc Endovasc Surg 2014; 47: 13-8.

14. Paravastu SC, Jayarajasingam R, Cottam R, et al. Endovascular repair of abdominal aortic aneurysm. Cochrane Database Syst Rev 2014; 1: CD004178.

15. Lederle F, Freischlag J, Kyriades T, et al. Outcomes following endovascular vs open repair of abdominal aortic aneurysm: a randomized trial. JAMA 2009; 302: 1535-42.

16. Prinssen M, Verhoeven EL, Buth J, et al. A randomized trial comparing conventional and endovascular repair of abdominal aortic aneurysms. N Engl J Med 2004; 351: 1607-18.

17. Greenhalgh RM, Brown LC, Kwong GP, et al. Comparison of endovascular aneurysm repair with open repair in patients with abdominal aortic aneurysm (EVAR trial 1), 30-day operative mortality results: randomised controlled trial. Lancet 2004; 364: 843-8.

18. Ziaja K, Kuczmik W, Ziaja D, et al. Endovascular treatment of infrarenal aortic aneurysm - three years of experience. Chirur Pol 2003; 5: 129-43.

19. Morisaki K, Matsumoto T, Matsubara Y, et al. Elective endovascular vs. open repair for abdominal aortic aneurysm in octogenarians. Vascular 2016; 24: 348-54.

20. Schermerhorn ML, Bensley RP, Giles KA, et al. Changes in abdominal aortic aneurysm rupturę and short-term mortality, 1995-2008: a retrospective observational study. Ann Surg 2012; 256: 651-8.

21. Budtz-Lilly J, Venermo M, Debus S, et al. Editor's choice - assessment of international outcomes of intact abdominal aortic aneurysm repair over 9 years. Eur I Vasc Endovasc Surg 2017; 54: 13-20.

22. IMPROVE Trial Investigators, Powell JT, Sweeting MJ, et al. Endovascular or open repair strategy for ruptured abdominal aortic 
aneurysm: 30 day outcomes from IMPROVE randomised trial. BMJ 2014; 348: f7661.

23. Krenzien F, Matia I, Wiltberger G, et al. Outcome after open surgery repair in endovascular-suitable patients with ruptured abdominal aortic aneurysms. Vasa 2013; 42: 442-8.

24. Holt PJ, Karthikesalingam A, Poloniecki JD, et al. Propensity scored analysis of outcomes after ruptured abdominal aortic aneurysm. Br J Surg 2010; 97: 496-503.

25. Ten Bosch JA, Willigendael EM, Kruidenier LM, et al. Early and mid-term results of a prospective observational study comparing emergency endovascular aneurysm repair with open surgery in both ruptured and unruptured acute abdominal aortic aneurysms. Vascular 2012; 20: 72-80.

26. De Rango P, Simonte G, Manzone A, et al. Mortality risk for ruptured abdominal aortic aneurysm in women. Ann Vasc Surg 2017; 39: 143-51.

27. Tan TW, Eslami M, Rybin D, et al. Outcomes of endovascular and open surgical repair of ruptured abdominal aortic aneurysms in elderly patients. J Vasc Surg 2017; 66: 64-70.

Received: 29.08.2017, accepted: 3.12 .2017 